\title{
Macrophage migration inhibitory factor of the parasitic nematode Trichinella spiralis
}

\author{
Timothy H. P. TAN*, Steve A. V. EDGERTON*, Rashmi KUMARI*, Mark S. B. MCALISTER $\dagger$, S. Mark ROWE $\ddagger$, Sylvia NAGL§, \\ Laurence H. PEARL†, Murray E. SELKIRK\|, Albert E. BIANCO $\mid$, Nicholas F. TOTTY**, Chris ENGWERDA*, Carolyn A. GRAY*1 \\ and David J. MEYER ${ }^{\star 2}$ \\ ${ }^{*}$ Department of Infectious and Tropical Diseases, London School of Hygiene and Tropical Medicine, Keppel Street, London WC1E 7HT, U.K., †Department of \\ Crystallography, Birkbeck College, Malet St., London WC1E 7HX, U.K., \$The Institute for Cancer Research, Chester Beatty Laboratories, 237 Fulham Road, \\ London SW6 6JB, U.K., §Department of Biochemistry and Molecular Biology, University College London, Darwin Building, Gower St., London WC1E 6BT, U.K., \\ \|Department of Biochemistry, Imperial College of Science Technology and Medicine, London SW7 2AY, U.K., TLiverpool School of Tropical Medicine, \\ Pembroke Place, Liverpool L3 5QA, U.K., and **Protein Analysis Laboratory, Imperial Cancer Research Fund, 44 Lincoln's Inn Fields, London WC2A 3PX, U.K.
}

cDNAs were obtained for macrophage migration-inhibitory factor (MIF)/L-dopachrome methyl ester tautomerase homologues from the parasitic nematodes Trichinella spiralis (TsMIF) and Trichuris trichiura (TtMIF). The translated sequences, which were partly confirmed by sequencing of proteolytic fragments, show 42 and $44 \%$ identity respectively with human or mouse MIF, and are shorter by one C-terminal residue. Unlike vertebrate MIF and MIF homologues of filarial nematodes, neither TsMIF nor TtMIF contain cysteine residues. Soluble recombinant TsMIF, expressed in Escherichia coli showed secondary structure (by CD spectroscopy) and quaternary structure (by light-scattering and gel filtration) similar to that of the trimeric mammalian MIFs and D-dopachrome tautomerase. The catalytic specificity of recombinant TsMIF in the ketonization of phenylpyruvate $\left(1.4 \times 10^{6} \mathrm{M}^{-1} \cdot \mathrm{s}^{-1}\right)$ was comparable with that of human MIF, while that of $p$-hydroxyphenylpyruvate $\left(9.1 \times 10^{4} \mathrm{M}^{-1} \cdot \mathrm{s}^{-1}\right)$ was 71 -fold lower. TsMIF showed high specificity in tautomerization of the methyl ester of L-dopachrome compared with non-esterified L-dopachrome ( $>87000$-fold) and a high $k_{\text {cat }}\left(\approx 4 \times 10^{4} \mathrm{~s}^{-1}\right)$. The crystal structure, determined to $1.65 \AA$ ( $1 \AA=0.1 \mathrm{~nm}$ ), was generally similar to that of human MIF, but differed in the boundaries of the putative active-site pocket, which can explain the low activity towards $p$-hydroxyphenylpyruvate. The central pore was blocked, but was continuous, with the three putative tautomerase sites. Recombinant TsMIF $(5 \mathrm{ng} / \mathrm{ml}-5 \mathrm{pg} / \mathrm{ml})$ inhibited migration of human peripheralblood mononuclear cells in a manner similar to that shown by human MIF, but had no effect from 5 to $500 \mathrm{ng} / \mathrm{ml}$ on anti-CD3stimulated murine T-cell proliferation. TsMIF was detected in supernatants of $T$. spiralis larvae cultured in vitro at $6 \mathrm{ng} / \mathrm{ml}$ (55 ng/mg total secreted protein). In conclusion TsMIF has structural, catalytic and cell-migration-inhibitory properties which indicate that it is partially orthologous to mammalian MIF.

Key words: cytokine, dopachrome, tautomerase, Trichuris.

\section{INTRODUCTION}

Parasitic helminths are remarkable for their ability to survive for long periods in constant interface with the protective immune systems of their host. Numerous immune-protective and immuneevasive mechanisms have been described, including surface shedding, resurfacing with host molecules, rapid tissue relocation, antioxidant defence systems and the production of immunomodulatory factors [1,2]. The nematode Trichinella spiralis is able to parasitize a wider range of mammalian species than any other helminth. The larva invades a muscle cell transforming it into a nurse cell, which is a stable intracellular niche unique among helminths. The nurse cell secretes a collagen capsule and stimulates angiogenesis. Infection with $T$. spiralis results in depression of various parameters of immunity, including delayed type hypersensitivity and responses to bacterial lipopolysaccharide [3,4]. However, little is known about the immunological interactions which support this host-parasite relationship.
A homologue of macrophage migration-inhibitory factor (MIF) was the first molecule isolated from $T$. spiralis showing similarity to a mammalian cytokine and which might contribute to subversion of host defences [5].

Mammalian MIF has shown a bewildering array of cellular effects. It is inhibitory not only towards monocyte-macrophage migration, but also glucocorticoid activity [6], immunoglobulin synthesis [7], natural killer-cell activity [8] and p53-dependent apoptosis [9]. MIF also shows positive effects on T-lymphocyte activation [10], insulin release [11], angiogenesis [12], fibroblast growth [13], sepsis [14] and macrophage nitric oxide synthesis [15]. Recently, the identification of an intracellular interaction of MIF with Jab1, a co-activator of activator protein-1 ('AP-1') transcription which increases the expression of pro-inflammatory genes, and promotes degradation of the cyclin-dependent kinase inhibitor $\mathrm{p} 27^{\mathrm{kip} 1}$, indicates how MIF may be involved in the control of the cell cycle [16]. MIF is genetically [17,18] and structurally [19] related to 'D-dopachrome tautomerase' with

Abbreviations used: AMSH, a signal-transducing adaptor protein involved in interleukin-2- and granulocyte-macrophage-colony-stimulating-factorstimulated cell growth; MIF, macrophage migration-inhibitory factor; (r)TsMIF, (recombinant) Trichinella spiralis MIF; TtMIF, Trichuris trichiura MIF; HsMIF, Homo sapiens (human) MIF; PDB, Protein Databank (Brookhaven, CT, U.S.A.); CC, correlation coefficient; IL, interleukin; IFN- $\gamma$, interferon- $\gamma$; CNS, Crystallography and NMR System; NCS, non-crystallographic symmetry.

1 Present address: Liverpool School of Tropical Medicine, Pembroke Place, Liverpool L3 5QA, U.K.

2 To whom correspondence should be addressed (e-mail david.meyer@Ishtm.ac.uk).

The nucleotide sequence data discussed are available from the DDBJ, EMBL, GenBank ${ }^{\mathbb{R}}$ and GSDB Nucleotide Sequence Databases under the accession numbers AJ012740 (Trichinella spiralis MIF), AJ237770 (Trichuris trichiura MIF) and AJ237610 (for partial T. trichiura AMSH); the crystal structure co-ordinates of $T$. spiralis MIF are in the PDB (file 1HFO). 
which MIF shares the spurious enzyme activity. The crystal structure of rat, human and mouse MIF is a unique trimeric barrel forming a narrow pore [20,21]. The monomer has a secondary structure similar to that of the dimer of interleukin-8 (IL-8) [21]. The tautomerase activity is associated with the Nterminal proline residue, which has a relatively low $\mathrm{p} K_{\mathrm{a}}$ [22-24]. MIF homologues have also recently been found in several filarial nematodes: Brugia pahangi, B. malayi, Wuchereria bancrofti and Onchocerca volvulus and the intestinal nematode Trichuris muris [5,25]. Immunocross-reactive material was also detected in $\mathrm{As}$ caris lumbricoides (human roundworm) and Dirofilaria immitis (dog heartworm) [25] and a novel MIF homologue from the human whipworm, Trichuris trichiura is presented herein.

To facilitate study of the possible role(s) of $T$. spiralis MIF (TsMIF) in parasite-directed subversion of host immunoregulation, it has been cloned, expressed in Escherichia coli and characterized with respect to structural, enzymic and cytokine properties.

\section{EXPERIMENTAL \\ Organisms}

$T$. spiralis larvae were obtained by pepsin digestion of infected mouse muscle [26] and snap-frozen. T. trichiura adults for Trichuris trichiura MIF (TtMIF) isolation were provided by Dr M. Albonico (Public Health Laboratory, Ivo de Carneri, Zanzibar, Tanzania) and Dr Q. D. Bickle (London School of Hygiene and Tropical Medicine, London, U.K.). They were collected from $48 \mathrm{~h}$ stool samples of mebendazole-treated children in Pember, Zanzibar, and frozen. T. trichiura adults for RNA isolation were obtained during investigative colonoscopy for chronic inflammatory bowel syndrome (Mona Campus, University of the West Indies, Jamaica) and snap-frozen.

\section{Isolation and characterization of TtMIF}

T. trichiura adults $(1.2 \mathrm{~g})$ were powdered in a pestle and mortar under liquid nitrogen and the L-dopachrome methyl ester tautomerase activity (putative TtMIF, see below for assay) purified from the soluble extract using a $1 \mathrm{ml}$ column of phenyl-agarose as described for the isolation of MIF homologues from T. muris and $B$. pahangi [5]. Purity was assessed by reverse-phase HPLC [5] and SDS/PAGE. Automated Edman sequencing was performed on 20 pmol of intact TtMIF using fast-cycle chemistry on an Applied Biosystems Procise HT sequencer [27]. A 50 pmol portion of TtMIF was digested overnight with immobilized trypsin in $25 \mathrm{mM}$ ammonium bicarbonate at $37^{\circ} \mathrm{C}$. Peptides were separated by reverse-phase HPLC using a $0.8 \mathrm{~mm} \times 150 \mathrm{~mm}$ column and sequenced as above.

\section{Primary structure of native TsMIF}

Native TsMIF, isolated from the soluble extract of $T$. spiralis larvae by phenyl-agarose chromatography and cation-exchange FPLC [5] was digested in $0.1 \mathrm{M}$ sodium bicarbonate with endoprotease Glu-C (Boehringer) followed by trypsin, and fragments purified by reverse-phase HPLC were sequenced using an Applied Biosystems 470A sequencer.

\section{cDNA isolation}

The cDNAs coding for both TsMIF and TtMIF were isolated using 3'-rapid amplification of cDNA ends. The primers TsM-F (5'-GCGGCTGCGAATTCATGCCWATYTTYACIYTBAA-
YAC-3') and TtM-F (5'-GCGGCTGCGAATTCATGCCWATYTTYACRTTYWSIAC- $3^{\prime}$ ) were designed from the N-terminal amino acid sequences of TsMIF [5] and TtMIF (P81529 and P81748 respectively). The nucleotide sequence degeneracy was restricted according to the codon usage of Caenorhabditis elegans as used for selecting another T. spiralis cDNA [28].

TsMIF cDNA was isolated from $T$. spiralis muscle-stage larvae powdered under liquid nitrogen. Total RNA was obtained using the RNeasy Midi Kit (Qiagen), and first-strand cDNA synthesized using the SuperScript Preamplification System (Life Technologies) with primer MRSdT. The initial PCR reaction mixture consisted of PCR buffer mix containing $3.0 \mathrm{mM} \mathrm{Mg}^{2+}$, $4 \%$ (v/v) DMSO, $2 \mu 1$ of $T$. spiralis cDNA and 1 pmol of primer TsM-F. During the first cycle, amplification was carried out at $94{ }^{\circ} \mathrm{C}$ for $180 \mathrm{~s}, 48^{\circ} \mathrm{C}$ for $60 \mathrm{~s}$ and $72{ }^{\circ} \mathrm{C}$ for $300 \mathrm{~s}$. Immediately after the denaturing step of the second cycle, $0.2 \mathrm{pmol}$ of primers MRS (5'-GGGGAATTCGATATCGGTACCT-3') and 5TM (5'-GCGGCTGCGAATTCATG-3') were added to the original PCR reaction mixture. For cycles $2-45$, amplification was carried out at $94{ }^{\circ} \mathrm{C}$ for $30 \mathrm{~s}, 54{ }^{\circ} \mathrm{C}$ for $30 \mathrm{~s}$ and $72{ }^{\circ} \mathrm{C}$ for $90 \mathrm{~s}$. The DNA polymerase used was TaqPlus Precision (Stratagene) or $\mathrm{Vent}_{\mathrm{R}}$ (New England Biolabs) for blunt-end cloning.

$T$. trichiura RNA was obtained by powdering worms under liquid nitrogen and extracting with guanidinium thiocyanate. Polyadenylated RNA was separated using an oligo-dT spun column and double-stranded cDNA synthesized using Moloneyleukaemia-virus reverse transcriptase and the klenow fragment of DNA polymerase I. Two sets of PCR were used to isolate the TtMIF cDNA. In the first PCR, the reaction mixture contained PCR buffer mix plus $1.5 \mathrm{mM} \mathrm{Mg} \mathrm{Mg}^{2+}, 4 \%$ DMSO, $2 \mu 1$ of $T$. trichiura cDNA, 1 pmol of primer MRSdT (5'-GGGGAATTCGATATCGGTACCdT $_{16}-3^{\prime}$ ) and $\mathrm{Vent}_{\mathrm{R}}$ DNA polymerase. This PCR was carried out at $94{ }^{\circ} \mathrm{C}$ for $30 \mathrm{~s}, 42^{\circ} \mathrm{C}$ for $30 \mathrm{~s}$, and $72{ }^{\circ} \mathrm{C}$ for $60 \mathrm{~s}$ for 35 cycles. Approx. $5 \%$ of this PCR mixture was used as the template for the second PCR, which was carried out as described above for TsMIF using primer TtM-F.

The PCR products from both $T$. spiralis cDNA and T. trichiura cDNA were cloned directly into pGEM-T Easy Vector (Promega) and recombinant plasmids were sequenced using the Thermo Sequenase dye terminator cycle sequencing kit (Amersham Life Sciences) and M13 primers.

\section{Expression of rTsMIF (recombinant TsMIF)}

The TsMIF PCR product was restricted with EcoRI, cloned into EcoRI-restricted pKK223-3 expression vector (Pharmacia Biotech) and transformed into E. coli JM109 competent cells (Promega). Colonies with recombinant plasmids were then cultured in liquid and induced with $1 \mathrm{mM}$ isopropyl thio- $\beta$-Dgalactopyranoside. After $3 \mathrm{~h}$ culture, cells were pelleted, sonicated in homogenization buffer $[150 \mathrm{mM} \mathrm{NaCl} / 1 \mathrm{mM}$ EDTA/ $50 \mu \mathrm{M}$ PMSF $/ 1 \mu \mathrm{M}$ leupeptin $/ 20 \mathrm{mM}$ sodium phosphate ( $\mathrm{pH}$ 7.0)] and the soluble extract obtained by ultracentrifugation. The extracts were tested for rTsMIF expression by SDS/PAGE and L-dopachrome methyl ester tautomerase activity (see below).

rTsMIF was purified from a positively expressing clone as follows. The soluble extract, obtained as above, from a $500 \mathrm{ml}$ exponential-phase bacterial culture was applied to a $3 \mathrm{ml}$ column of phenyl-agarose in homogenization buffer at $4{ }^{\circ} \mathrm{C}$. The column was washed thoroughly with this buffer (minus protease inhibitors), and the rTsMIF subsequently eluted with EGEP buffer $[40 \%(\mathrm{v} / \mathrm{v})$ ethylene glycol/1 mM EDTA/20 mM sodium phosphate ( $\mathrm{pH} 7.0)]$, the eluate being monitored for Ldopachrome methyl ester tautomerase activity. A stock of $0.5 \mathrm{mg} / \mathrm{ml} \mathrm{TsMIF}$ was kept in this solution at $4{ }^{\circ} \mathrm{C}$. Portions 
were dialysed against PBS and re-applied to phenyl-agarose in this buffer and eluted with $20 \mathrm{mM}$ Hepes, $\mathrm{pH}$ 7.2. After sterile filtration such solutions of TsMIF of approx. $50 \mu \mathrm{g} / \mathrm{ml}$ were stored at $4{ }^{\circ} \mathrm{C}$ and diluted into tissue-culture medium for cellular studies. A larger amount of rTsMIF for structural analysis was prepared from 5 litres of induced culture. Cells were disrupted with a French press and the soluble supernatant after ultracentrifugation was applied to a column of phenyl-agarose and thoroughly washed as described above. TsMIF was then eluted with a linear gradient from $150 \mathrm{mM} \mathrm{NaCl} / 1 \mathrm{mM}$ EDTA/20 mM sodium phosphate, $\mathrm{pH} 7.0$, into $20 \mathrm{mM} \mathrm{mM}$ Hepes, $\mathrm{pH} 7.0$, over 5 column volumes and then concentrated by ultrafiltration and further purified on a Superdex 75 column $(100 \mathrm{~cm} \times 2.5 \mathrm{~cm})$ in $20 \mathrm{mM}$ Hepes, $\mathrm{pH}$ 7.0. The concentration of purified TsMIF samples were estimated from $A_{280}\left(\epsilon_{280}=8250 \mathrm{M}^{-1} \cdot \mathrm{cm}^{-1}\right)$, and purity was determined by reverse-phase HPLC and SDS/PAGE.

Freeze-dried purified recombinant human MIF (rHsMIF) was obtained from Dr Andrej Francky (BioHit d.o.o., Ljubljana, Slovenia) and solutions prepared in EGEP buffer and sterile Hepes equivalent to those for rTsMIF (see above). The thiol content of rHsMIF was $2.2 \pm 0.1 \mathrm{~mol} /$ monomer, determined by titration with $2,2^{\prime}$-dithiobis(nitrobenzoic acid) in guanidinium chloride [29].

\section{Structural studies of TsMIF in solution}

MS

Mass spectra were collected on a VG Platform electrospray mass spectrometer (Micromass). Samples were desalted by dialysis against deionized water for $24 \mathrm{~h}$. Samples were then injected $(10 \mu \mathrm{l})$ under standard conditions $(80-200 \mathrm{pmol} / \mu \mathrm{l}$ in $50 \%$ acetonitrile $/ 0.25 \%$ formic acid). Delivery solvent ( $50 \%$ acetonitrile) was pumped at a flow rate of $10 \mu \mathrm{l} / \mathrm{min}$. Twelve $10 \mathrm{~s}$ scans were accumulated for each sample over the $m / z$ range $750-1150$. The source temperature was set at $45^{\circ} \mathrm{C}$ and the cone voltage was $41 \mathrm{~V}$. Spectra were processed using the Masslynx software supplied with the instrument (version 3.0 b5). Horse heart myoglobin (molecular mass $16951.5 \mathrm{Da}$ ) was used to calibrate the instrument [30].

\section{CD spectroscopy}

CD spectra were recorded using a nitrogen-flushed Aviv 202SF spectropolarimeter with samples in $0.01-1.0-\mathrm{cm}$-path-length quartz cells at room temperature. The protein concentrations of samples ranged from 0.2 to $10 \mathrm{mg} / \mathrm{ml}$, in $20 \mathrm{mM}$ Hepes buffer, $\mathrm{pH}$ 8.0. Wavelength scans were recorded five times using a $0.2 \mathrm{~nm}$ step size and a $2 \mathrm{~s}$ averaging time. The averaged spectra were imported into a spreadsheet program (Origin) and corrected for baseline drift and then smoothed. Estimates of secondarystructural content were determined by quantitative analysis of the spectra using linear least squares [31] and singular value decomposition [32]. A value of $<0.1$ for the normalized rootmean-square deviation for each curve is indicative of a good fit [33].

\section{Gel filtration}

Size-exclusion chromatography was performed using a HiPrep Sephacryl S-100 column ( $16 \mathrm{~mm} \times 60 \mathrm{~mm}$; Pharmacia $)$ controlled by an Acta FLPC system. The column was run in $20 \mathrm{mM}$ $\mathrm{NaCl} / 20 \mathrm{mM}$ Hepes, $\mathrm{pH} 8.0$, at $0.5 \mathrm{ml} / \mathrm{min}$, using $1 \mathrm{ml}$ sample volumes containing $0.1-1 \mathrm{mg}$ of protein.

\section{Light-scattering}

Dynamic light-scattering measurements were obtained using a DynaPro-801 instrument equipped with a $100 \mu \mathrm{l}$ cell (Protein Solutions, Charlottesville, VA, U.S.A.). Samples of TsMIF, at concentrations of 2,5 and $10 \mathrm{mg} / \mathrm{ml}$ in $20 \mathrm{mM}$ Hepes $/ 20 \mathrm{mM}$ $\mathrm{NaCl}, \mathrm{pH} 8.0$, were passed through $0.2 \mu \mathrm{m}$-pore-size membrane filters (Whatman) during injection. Measurements were taken at room temperature $\left(21.2 \pm 0.16^{\circ} \mathrm{C}\right)$, and data was analysed using Autopro software, which calculated the translational diffusion coefficient, $D_{T}$, and thence the apparent Stokes radii. The instrument was calibrated with a set of 23 standard proteins ranging in size from 8 to $1250 \mathrm{kDa}$, allowing reliable estimation of molecular mass from measurements of diffusion coefficients. The photon count rate varied by less than $3 \%$ in all experiments. Sum of squares errors for all readings were less than 0.5 , indicating that the data was of high quality with a high signal-tonoise ratio.

\section{Tautomerase activities}

For tautomerase assays, MIF stocks $(0.5 \mathrm{mg} / \mathrm{ml})$ in EGEP buffer were diluted 20-100-fold in the same buffer and kept on ice. Dopachrome tautomerase activity was measured spectrophotometrically at $32{ }^{\circ} \mathrm{C}$ in $10 \mathrm{mM}$ sodium phosphate $/ 0.5 \mathrm{mM}$ EDTA, pH 6.4, using $0.4 \mathrm{mM} \mathrm{L-3,4-dihydroxyphenylalanine} \mathrm{or}$ its methyl ester or the D-enantiomer plus limiting sodium $\mathrm{m}$ periodate to generate the dopachromes immediately prior to addition of MIF [34]. An $\epsilon_{474}$ of $3700 \mathrm{M}^{-1} \cdot \mathrm{cm}^{-1}$ was used for each dopachrome. Specific activities were obtained from the mean values from triplicate assays differing by less than $12 \%$.

Approximate kinetic data for the relatively rapid tautomerization of L-dopachrome methyl ester were obtained from desaturation curves as follows: to $0.55 \mathrm{mM}$ L-dopachrome methyl ester was added sufficient recombinant MIF to catalyse about $70 \%$ tautomerization in $3 \mathrm{~min}$ and the end point obtained by addition of an excess of enzyme. Tangential rates were determined from the curve at 10-12 substrate concentrations. The non-catalytic rate at these substrate concentrations was subtracted by reference to tangential rates from a similar assay lacking enzyme. Since the $K_{\mathrm{m}}$ values were approx. 10-fold higher than the maximum substrate concentration range studied, approximate kinetic data only were obtained from double-reciprocal plots.

The tautomerization (ketonization) of phenylpyruvate and $p$ hydroxyphenylpyruvate was assayed at 288 and $300 \mathrm{~nm}$ respectively at $23{ }^{\circ} \mathrm{C}$ [35]. Specific activities were obtained using $0.1 \mathrm{mM}$ substrate, and kinetic data were obtained from desaturation curves as described above. The data were fitted to a rectangular hyperbola using the Kinenort software (Dr A. G. Clark, University of Wellington, Wellington, New Zealand) to obtain kinetic constants.

\section{Crystal structure of TsMIF}

\section{Crystallization and data collection}

TsMIF protein at $33 \mathrm{mg} / \mathrm{ml}$ was screened for crystallization using the commercial Hampton Crystallization Screens I and II [36]. The trials were carried out under oil using the microbatch method. Crystals were observed under 12 of the 98 conditions. Four conditions showing the best initial crystals were optimized in hanging drops to give diffraction-quality crystals. The highest diffracting crystals were grown with final conditions in the crystallization drop of $16.5 \mathrm{mg} / \mathrm{ml}$ TsMIF, $400-600 \mathrm{mM}$ ammonium acetate, $30-36 \%$ 4000- $M_{\mathrm{r}}$ poly(ethylene glycol) ('PEG4K') and $100 \mathrm{mM}$ sodium acetate at $\mathrm{pH}$ 4.6. After initial 
Table 1 Diffraction and refinement data

\begin{tabular}{ll}
\hline Parameter & Value \\
\hline Total number of reflections & 163895 \\
Unique reflections & 67115 \\
Average multiplicity & 2.3 \\
Average $/ / \sigma{ }^{*}$ & 3.6 \\
Average completeness & 97.6 \\
Average $R_{\text {merge }}{ }^{\dagger}$ & 0.057 \\
Reflections in highest shell & 16174 \\
Unique in highest shell & 7060 \\
Multiplicity in highest shell & 2.2 \\
$\|^{*} \sigma{ }^{*}$ in highest shell & 2.5 \\
Completeness in highest shell & 97.6 \\
$R_{\text {merge }}{ }^{\dagger}$ in highest shell & 28.1 \\
Number of crystals & 1 \\
Number of protein atoms & 5134 \\
Number of water molecules & 1032
\end{tabular}

* $/ / \sigma /$ is average intensity in resolution bin/average S.D.

$\dagger R_{\text {merge }}=\left(\Sigma_{\text {hkl }}\left|I_{\text {hkl }}-\left\langle I_{\text {hk }}\right\rangle\right|\right) /\left(\Sigma_{\text {hkl }}\left|I_{\text {hkl }}\right|\right)$, where $I_{\text {hkl }}$ is the intensity for each observation/symmetry equivalent of a particular reflection, hkl, and $\left\langle I_{h k l}\right\rangle$ the average intensity over all observations/symmetry equivalents of the reflection $\left(0.057\right.$ refers to the overall $R_{\text {merge }}$ of the data and $28.1 \%$ (or 0.281 ) the $R_{\text {merge }}$ in the highest resolution bin).

in-house data collection on a RU300HB Rigaku generator to determine the cell, space-group and diffraction characteristics, a full data set was collected to $1.5 \AA(1 \AA=0.1 \mathrm{~nm})$ on beamline ID14-3 $(\lambda=0.931 \AA)$ at the ESRF (European Synchrotron Radiation Facility, Grenoble, France), using high- and lowresolution sweeps. The cell was refined to $a=110.10 \AA, b=$ $88.38 \AA, c=86.36 \AA$, $\beta=131.1^{\circ}$, space group C2. Calculation of the Matthews coefficient [37] indicated that the cell contained four molecules (equivalent to two molecules in the assymmetric unit), resulting in a solvent content of $43 \%$. The data was processed using MOSFLM and sorted, merged, scaled and truncated using programs from the CCP4 [38] suite of programs (Table 1).

\section{Structure determination and refinement}

The structure was solved by molecular replacement with the human MIF structure [PDB (Protein Database, Brookhaven, CT, U.S.A.) entry 1MIF] [20] using AMoRe contained in the CCP4 [38] suite of programs. Cross- rotation and translationfunction searches were carried out using data to $2.0 \AA$. The cross rotation yielded two unambiguous solutions [correlation coefficient $(\mathrm{CC})=22.2$ and $\mathrm{CC}=19.6$, next highest solution $\mathrm{CC}=10.5]$. The two solutions were refined as rigid bodies using data to $1.65 \AA$, giving a final CC of 65.5 .

Refinement was carried out using the slowcool-torsionalrefinement strategy in CNS (Crystallography and NMR System) version 1.0 [39]. Initially, sixfold non-crystallographic symmetry (NCS) was used in refinement. The NCS was relaxed to twofold and later removed in final cycles of refinement and model building. The model was manually rebuilt with the program $\mathrm{O}$ [40]. The model was stereochemically checked using PROCHECK [38]. Water molecules were located using the water-picking routine of CNS and checked manually in O before being included in refinement. The final $R=0.225$ and $R_{\text {free }}=$ 0.281 , with 1033 water molecules modelled. The structure has been deposited at the PBD as file 1HFO. $R$ (the crystallographic $R$-factor) is defined as follows:

$R=\left(\Sigma_{h k l}\left|F_{o b s}-F_{c a l c}\right|\right) /\left(\Sigma_{h k l}\left|F_{o b s}\right|\right)$

where $F_{\text {obs }}$ are the observed structure factor amplitudes and $F_{\text {calc }}$ those determined from the model. $R_{\text {free }}$ is $R$ but for $5 \%$ of the total number of reflections that have been excluded from the refinement process.

\section{Cellular studies}

Migration of human monocytes was studied using Transwell chemotaxis chambers $(6.5-\mathrm{mm}$-diameter polycarbonate filters with $5 \mu \mathrm{m}$ pores; Costar) using methods based on those in [25]. Monocytes were prepared from buffy coat of healthy volunteers (North Thames Blood Transfusion Service, Colindale, London, U.K.) after dilution with 5 vol. of medium A [RPMI 1640 medium (Gibco BRL) containing $25 \mathrm{mM}$ Hepes, $2 \mathrm{mM} \mathrm{L}$ glutamine, $1 \mathrm{mM}$ sodium pyruvate and $100 \mathrm{unit} / \mathrm{ml}$ penicillin/ $100 \mu \mathrm{g} / \mathrm{ml}$ streptomycin], by centrifugation on Ficoll gradient using Histopaque 1077 (Sigma). The monocyte fraction was washed and erythrocytes lysed with Tris/ $\mathrm{NH}_{4} \mathrm{Cl}$ buffer $(0.14 \mathrm{M}$ $\mathrm{NH}_{4} \mathrm{Cl} / 17 \mathrm{mM}$ Tris/HCl, pH 7.2). Cells were resuspended, counted and diluted to $2 \times 10^{6}$ cells $/ \mathrm{ml}$ together with purified MIF ( $5 \mathrm{ng}-5 \mathrm{pg} / \mathrm{ml}$ diluted from a $50 \mu \mathrm{g} / \mathrm{ml}$ stock in $20 \mathrm{mM}$ Hepes, pH 7.2) or, as a control, an equal volume of Hepes buffer lacking MIF. For migration-inhibition assay, the upper filter chambers were separated and $600 \mu \mathrm{l}$ of medium A was placed in the lower chambers. A $100 \mu 1$ portion of monocyte suspension (control or with added MIF) was then added to the upper chambers, each being immediately placed on to a lower chamber. Quadruplicate samples were prepared. After incubation at $37{ }^{\circ} \mathrm{C} / 5 \% \mathrm{CO}_{2}$ for $3 \mathrm{~h}$, the non-migrated cells on the upper surface of the filters were gently scraped off and the remainder removed by aspiration. The migrated cells on the lower surface were fixed with methanol and stained using a Diff Quick kit (Dade-Behring A. G., Duedingen, Switzerland). The membranes were mounted on glass slides in Deepex (BDH/Merck). The slides were coded and randomized prior to quantitative analysis. Migrated cells were counted in five random fields per filter. After unblinding, the 20 fields per sample were averaged, the S.D. calculated and the samples statistically compared by a two-tailed Student's $t$ test.

T-cell activation was studied using splenocytes isolated from female BALB/c mice and measuring proliferation and cytokine production. $\mathrm{CD}^{+} \mathrm{T}$ cells were isolated from splenocytes by positive selection using magnetically activated cell sorting according to the protocol provided by the manufacturer of the selection columns (MS +) and anti-CD4-antibody (L3T4)conjugated microbeads (Miltenyl Biotec, Bergisch Gladbach, Germany). Cells were cultured in 96-well, flat-bottomed plates [Nunc (now part of Life Technologies, Paisley, Renfrewshire, Scotland, U.K.)] and T cells were stimulated with $10 \mu \mathrm{g} / \mathrm{ml}$ immobilized (plate-bound) anti-CD3 $\epsilon$ mAb (145-2C11) in different concentrations of TsMIF solutions, and proliferation was measured after $36 \mathrm{~h}$ by incorporation of $\left[{ }^{3} \mathrm{H}\right]$ thymidine. Prior to the $\left[{ }^{3} \mathrm{H}\right]$ thymidine pulse (after $24 \mathrm{~h}$ of culture), $25 \mu \mathrm{l}$ of supernatant was removed and frozen for subsequent quantitative cytokine analysis. IL-2 and IL-4 production were measured using proliferation of a natural killer-cell line $\left(10^{4}\right.$ cells/well $)$, in the presence of neutralizing antibodies to IL-4 $(11 \mathrm{~B} 11,1 \mu \mathrm{g} / \mathrm{ml})$ and IL-2 (S4B6, $2 \mu \mathrm{g} / \mathrm{ml}$ ) respectively. After $24 \mathrm{~h}, 10 \mu \mathrm{l}$ of 3(4,5-dimethylthiazol-2-yl)-2,5-diphenyl-2 $H$-tetrazolium bromide ('MTT'; $5 \mathrm{mg} / \mathrm{ml}$ ) and $100 \mu \mathrm{l}$ of $0.04 \mathrm{M} \mathrm{HCl}$ in propan-2-ol were added to each well, and plates read in an ELISA reader. The assay detected $>0.25$ unit $/ \mathrm{ml}$ IL-2 and $>1$ unit $/ \mathrm{ml}$ IL-4. Interferon- $\gamma($ IFN- $\gamma)$ was measured by antibody-capture ELISA using anti-IFN- $\gamma(\mathrm{R} 46 \mathrm{~A} 2 ; 2 \mu \mathrm{g} / \mathrm{ml})$ to capture, and biotinylated anti-IFN- $\gamma$ (XMG1; $1 \mu \mathrm{g} / \mathrm{ml})$ for detection; the sensitivity was $>1 \mathrm{unit} / \mathrm{ml}$. Natural killer cells and antibodies used were 
provided by Dr R. Lawrence, Department of Biological Sciences, University of Manchester, Manchester, U.K.

\section{TsMIF secretion}

T. spiralis larvae from muscle of rats infected more than 1 month previously were washed extensively in water, and three times in sterile culture medium [serum-free RPMI-1640/0.25\% (w/v) glucose $/ 2 \mathrm{mM}$ L-glutamine $/ 100 \mathrm{unit} / \mathrm{ml}$ penicillin $/ 100 \mu \mathrm{g} / \mathrm{ml}$ streptomycin $/ 20 \mu \mathrm{g} / \mathrm{ml}$ gentamicin] prior to culture at $37^{\circ} \mathrm{C} / 5 \%$ $\mathrm{CO}_{2}$ for 3 days with a daily change of medium [41]. In some experiments, larvae were activated by incubation in at least 10 vol. of $5 \%$ bovine bile (Sigma) in PBS for $1 \mathrm{~h}$ at $37^{\circ} \mathrm{C}$ and washed three times in PBS prior to culture. Pooled secreted products in the medium were cleared through $0.2 \mu \mathrm{m}$-pore-size filters, dialysed against $20 \mathrm{mM}$ Hepes $/ 50 \mathrm{mM} \mathrm{NaCl}, \mathrm{pH} 7.5$, and concentrated using Centricon 10 microconcentrators (Amicon). TsMIF was measured in concentrated samples by its Ldopachrome methyl ester tautomerase activity (see above), and the assay was validated in one sample by purification on phenylagarose followed by reverse-phase HPLC (see above). Total protein in the medium and soluble extracts from larval homogenates was determined with the Biuret reagent.

\section{RESULTS}

\section{Isolation of TtMIF}

The dopachrome tautomerase (i.e. MIF) activity of $T$. trichiura soluble extract was purified to greater than $95 \%$ in a single step using phenyl-agarose chromatography, similar to that previously obtained for $T$. muris and B. pahangi [5]. A $5 \mu \mathrm{g}$ portion of TtMIF was obtained from $1.2 \mathrm{~g}$ of worms. The specific dopachrome tautomerase activity was $310 \mu \mathrm{mol} / \mathrm{min}$ per $\mathrm{mg}$ of protein. TtMIF, like other MIF proteins, gave a band of molecular mass $13 \mathrm{kDa}$ on SDS/PAGE.

\section{Primary structure of TsMIF and TtMIF}

The open reading frames of TsMIF and TtMIF cDNAs (Figure 1) correspond to proteins (lacking initiating methionine) of 113 amino acids - one residue less than mammalian or avian MIFs. Their calculated molecular masses were $12164.6 \mathrm{Da}$ and 12058.6 Da respectively. The sequences are in agreement with the partial protein sequences obtained by Edman degradation of wild-type material. A comparison of the primary structures of TsMIF and TtMIF with those of mammalian MIF and nematode MIF-like molecules (Figure 1) shows that TsMIF and TtMIF share between 25 and $46 \%$ protein sequence identity with other MIFs, including all of the uniformly conserved residues, but are notably lacking in cysteine residues.

An apparent pseudogene was also obtained during the cloning of TtMIF (AJ 237610). The DNA fragment yielded the correct sequence to encode the N-terminal five or six residues of TtMIF followed by a stop codon. The following nucleotide sequence yielded the deduced protein sequence, one reading frame removed, which was $63 \%$ identical with the Jab1 domain of human AMSH (a signal-transducing adaptor protein involved in interleukin-2- and granulocyte-macrophage-colony-stimulatingfactor-stimulated cell growth) [42].

\section{Expression of rTsMIF}

The PCR product of TsMIF cDNA was cloned into the nonfusion pKK223-3 expression vector and E. coli transformant

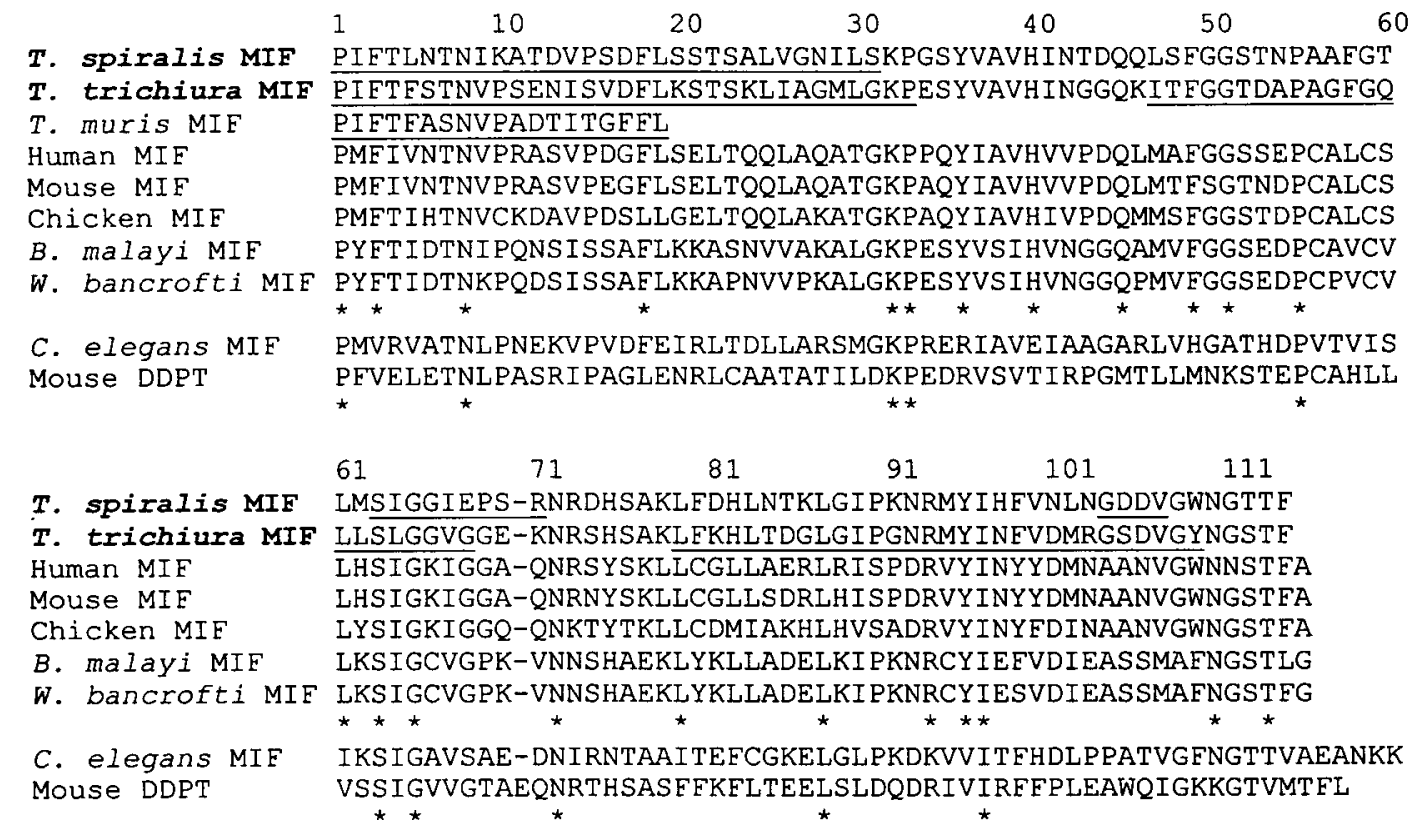

Figure 1 Comparison of primary sequence of TsMIF and TtMIF with vertebrate MIFs and D-dopachrome tautomerase, and other nematode MIF homologues

The sequences of TsMIF and TtMIF are aligned with the partial sequence of TmMIF [5] and the complete sequences of human MIF (Z23063), mouse MIF (Z23048), chicken MIF (M95776), B. malayi MIF-1 (AF002699), W. bancrofti MIF (AF040629), C. elegans MIF-1 (Z78012) and mouse D-dopachrome tautomerase ('DDPT') (AF012431). The sequences of TsMIF and TtMIF confirmed by automated Edman degradation are underlined. Highly conserved residues are indicated with asterisks $\left(^{*}\right)$. 
Table 2 Comparison of estimates of secondary structure composition derived from CD spectra with those from crystal structure for TsMIF and HsMIF

\begin{tabular}{lllll}
\hline \multirow{5}{*}{ MIF } & \multicolumn{4}{l}{ Percentage of structure as: } \\
\cline { 2 - 5 } & $\alpha$-Helix & $\beta$-Sheet & \multicolumn{1}{l}{$\beta$-Turn } & Unordered \\
\hline TsMIF* $^{*}$ & $18-25(26)$ & $43-58(30)$ & $6-14(7)$ & $15-26(37)$ \\
HsMIF $\dagger$ & $11-25(28)$ & $30-50(28)$ & $15-33(4)$ & $12-24(40)$
\end{tabular}

* Secondary-structure estimation from CD spectra was performed using the linear least squares [31] and singular-value decomposition [32] methods with reference data sets [33,44]; good-quality curve fits (normalized root-mean-square deviation $<0.1$ ) were obtained for secondary structure analysis using both methods; the secondary structure of crystalline TSMIF is given in parentheses.

$\dagger$ The range of secondary-structure composition of HsMIF using several different CD-based prediction methods estimates [43], and in parentheses the data from the crystal structure [20] (PDB code $1 \mathrm{MIF}$ ).

cultures carrying recombinant plasmids obtained. Addition of inducer to liquid cultures resulted in expression of soluble Ldopachrome methyl ester tautomerase activity and a detectable extra band of molecular mass $13 \mathrm{kDa}$ upon SDS/PAGE of the bacterial extract. The rTsMIF was purified from a $500 \mathrm{ml}$ culture for further study of enzymic and cytokine properties. A $3 \mathrm{mg}$ portion of rTsMIF was obtained with minimal losses. The recombinant enzyme showed a specific tautomerase activity similar to that of the enzyme purified from $T$. spiralis $(3500 \mu \mathrm{mol} / \mathrm{min}$ per $\mathrm{mg})$. Of three proteins detectable contaminating rTsMIF in the initial EGEP buffer eluate of the phenyl-agarose column, one, of molecular mass $58 \mathrm{kDa}$, appeared from SDS/PAGE analysis to be co-induced with TsMIF. It was purified by reverse-phase HPLC, and the first eight residues obtained by Edman degradation, which identified it as tryptophan indole lyase ( $\beta$-cysteine conjugate lyase). The molecular mass of rTsMIF, determined by electrospray-ionization MS matched the calculated mass of rTsMIF minus the Nterminal methionine residue within 1 mass unit, indicating that there were no further post-translational modifications to rTsMIF. Only one major peak was observed. A larger batch of rTsMIF (30 mg) was prepared for structural analysis.

\section{Secondary and quaternary structure of soluble TsMIF}

CD spectroscopy of rTsMIF indicated that it had a high secondary-structure content. Computational secondary-structure analysis [31-33] of the CD spectra suggested that structure of rTsMIF in solution comprised $18-25 \% \alpha$-helix, about $43-58 \%$ $\beta$-strands, $6-14 \% \beta$-turn and the remainder $15-26 \%$ random coil. These secondary-structure estimates were compared with CD-based secondary-structure analysis of HsMIF that used the same data sets [43] and were found to give similar values (Table 2). Essentially no change was observed in the CD spectra of rTsMIF over a 50 -fold concentration range $(0.2-10 \mathrm{mg} / \mathrm{ml})$.

The oligomeric state of soluble rTsMIF was assessed by sizeexclusion chromatography and dynamic light-scattering. By chromatography, the molecular mass was estimated at $25 \mathrm{kDa}$. The elution volume was independent of protein concentration over the range $0.1-10 \mathrm{mg} / \mathrm{ml}$, suggesting that the rTsMIF oligomer is relatively stable. This apparent mass agrees closely with that of rat MIF estimated by gel filtration $(24.3 \mathrm{kDa})$, which was subsequently found to be a trimer in the crystal structure. Dynamic-light-scattering analyses were performed with rTsMIF samples at both 5 and $10 \mathrm{mg} / \mathrm{ml}$. Ten separate readings were made for both samples at room temperature. Essentially identical diffusion coefficients $\left[(894 \pm 3.18) \times 10^{-13} \mathrm{~m}^{2} / \mathrm{s}\right]$ were observed at both protein concentrations. Baseline values of between 1.000 and 1.001 indicated that the distribution was monomodal and could be fully resolved by a single autocorrelation decay function. Low values for polydispersity $(0.483 \pm 0.08 \mathrm{~nm})$ were observed, suggesting that rTsMIF was essentially monodispersed over this concentration range. Comparison of the diffusion coefficient of rTsMIF with those of a range of molecular-mass standards gave an estimated molecular mass of $\approx 30 \mathrm{kDa}$, consistent with trimeric self-association of rTsMIF. The estimated molecular radius of rTsMIF $(2.4 \mathrm{~nm})$ is similar to that of human MIF $(2.6-2.7 \mathrm{~nm})$ previously measured by this technique [45].

\section{Tautomerase activity}

The specific tautomerase activity of TsMIF towards Ldopachrome methyl ester was about 6-fold higher than that of mammalian MIFs as also was its specificity, as judged by relative activity towards unesterified D-dopachrome (7000-fold compared with 72.5 -fold lower respectively; Table 3 ). Since the $K_{\mathrm{m}}$ for L-

Table 3 Tautomerase activities of TsMIF compared with those of human MIF

Specific activities were measured as initial rates over 0.4 min using $0.4 \mathrm{mM}$ substrate at $32^{\circ} \mathrm{C}, \mathrm{pH} 6.4$, for the dopachromes and with $100 \mu \mathrm{M}$ substrate at $23{ }^{\circ} \mathrm{C}$, pH 6.5 for the phenylpyruvates. Kinetic constants were obtained from desaturation curves.

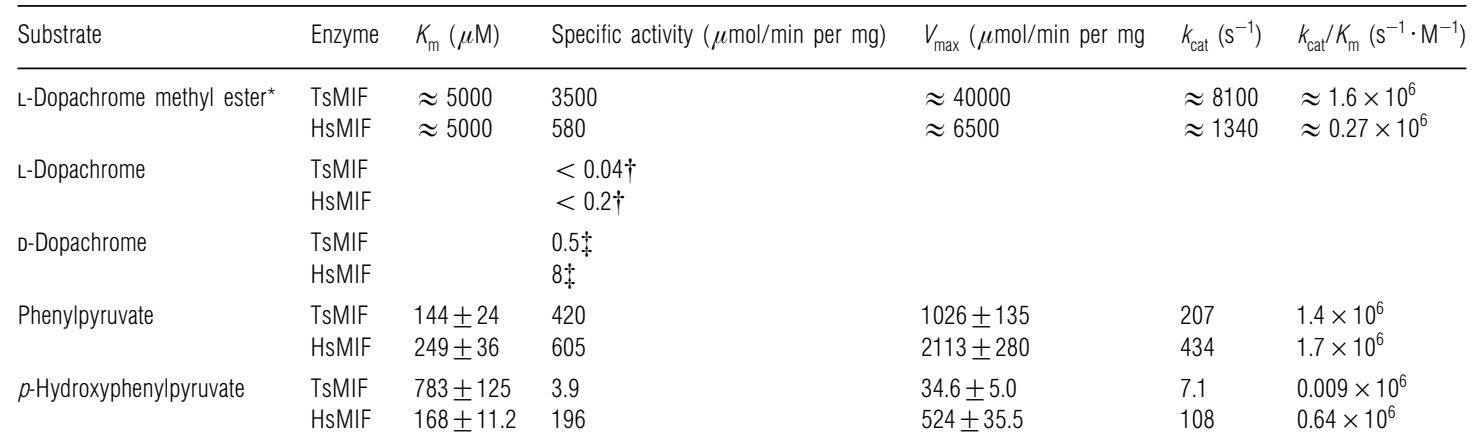

* $K_{\mathrm{m}}$ values too high for accurate kinetic analysis.

†Detectability limit.

Activity too low for kinetic analysis. 


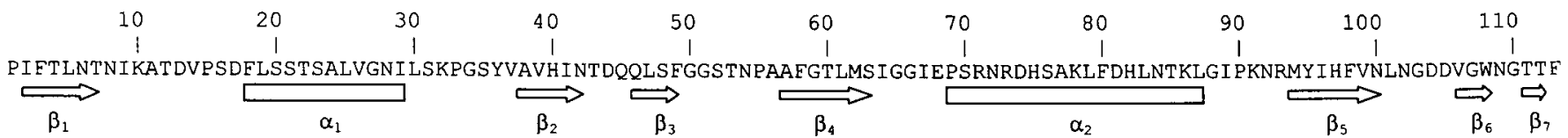

Figure 2 Secondary structure assignments of crystalline TsMIF

Secondary structure was assigned as described in [46].

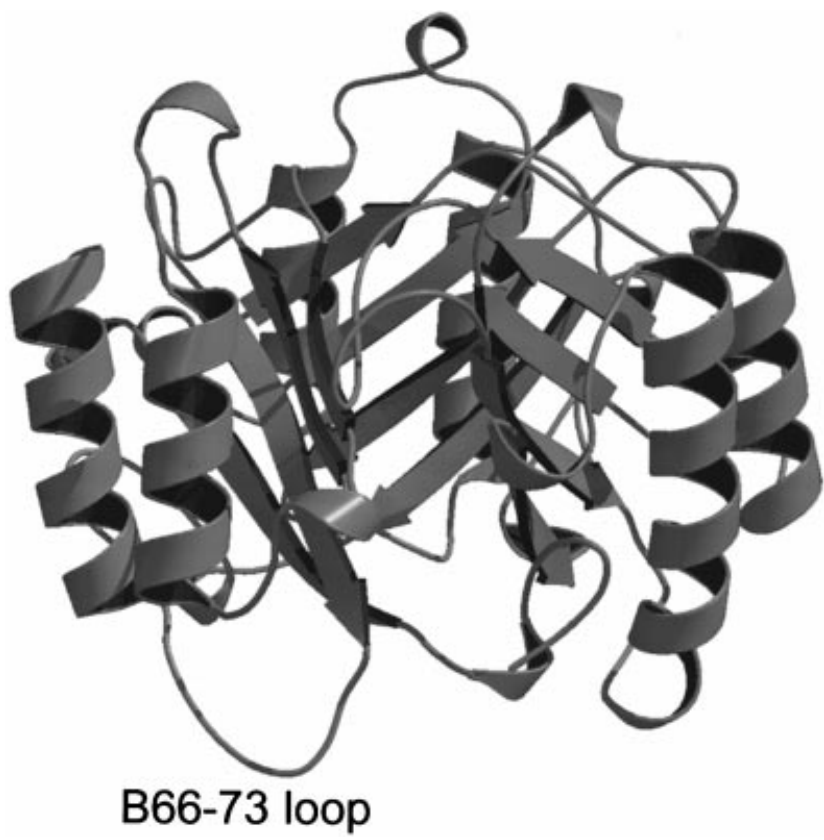

Figure 3 Side view of TsMIF showing secondary structure elements and the disordered loop B66-B73

The Figure was prepared using BOBSCRIPT [47].

dopachrome methyl ester was inaccessibly high, only approximate kinetic data could be obtained. The approximate $k_{\text {eat }}$ of $8000 \mathrm{~s}^{-1}$ and catalytic specificity greater than $10^{6} \mathrm{M}^{-1} \cdot \mathrm{s}^{-1}$ are notable. Catalysis of the ketonization of the physiological substrates phenylpyruvate and $p$-hydroxyphenylpyruvate by human MIF also yielded catalytic specificities in the region of $10^{6} \mathrm{M}^{-1} \cdot \mathrm{s}^{-1}$ similar to published values [35] (Table 3). TsMIF showed a similar activity towards phenylpyruvate, but had a lower $k_{\text {cat }}$ and higher $K_{\mathrm{m}}$ than HsMIF towards $p$-hydroxyphenylpyruvate, resulting in a 71-fold lower catalytic specificity.

\section{Crystal structure}

The secondary and tertiary structure of TsMIF [Figures 2 and 3, and $\mathrm{PDB}$ file $1 \mathrm{HFO}$ ] is very similar to HsMIF, as expected from the high CCs seen during the molecular replacement. In both cases the amount of $\beta$-sheet was less than, and the amount of 'unordered' structure greater than, that estimated from the CDspectroscopic analysis (Table 2). TsMIF forms a trimer of approximate dimensions $50 \AA \times 50 \AA \times 40 \AA$. Each monomer consists of a central core of a four-stranded $\beta$-sheet flanked by two anti-parallel helices and a further three very short $\beta$-strands. The short $\beta$-strands extend the core four-stranded $\beta$-sheet of a neighbouring monomer on either side, to create a seven-stranded $\beta$-sheet, thus linking the trimer together (Figure 3). The protein shows several areas of secondary structure that have high mobility. The most obvious is the loop between position B66 to B73. This clearly exists in at least two conformations. It is not known if this has any functional relevance. The 10-18 loop in chains B,C,D and F is also highly mobile, though does not show any signs of alternate conformations. This loop lies on the top surface of the protein. The equivalent loop in chains $\mathrm{A}$ and $\mathrm{F}$ are less mobile due to intermolecular contacts within the crystal.

A channel is formed down the centre of the trimer from the $\mathrm{N}$ and C-terminal end (Figure 4), which is closed at the other end by a ring formed from the side chains of $\mathrm{Asn}^{42}$ and the conserved Gln ${ }^{45}$ from each monomer. In contrast the narrowest point of the channel in HsMIF, which has a valine residue at position 42, is 3-4 $\AA$. Interestingly, position 42 is also asparagine in TtMIF and the Brugia MIFs (Figure 1). The channel has no large areas of either positive or negative charge, and overall is very slightly negatively charged.

\section{Active site}

A comparison of the putative tautomerase active site of TsMIF with that of HsMIF (Figure 5) shows a close overlap of the active-site residue Pro $^{1}$ and the residues closely surrounding it: $\mathrm{Ser}^{63}, \mathrm{Lys}^{32}$ and the aromatic grouping $\mathrm{Tyr}^{36}, \mathrm{Phe}^{\mathrm{B} 49}, \mathrm{Tyr}^{\mathrm{B} 95}$, $\mathrm{Phe}^{113}$ and $\operatorname{Trp}^{108}$. Electron density is seen in the putative activesite pocket of some subunits very close to $\operatorname{Pro}^{1}$ (PDB file 1HFO), indicative of a bound ligand.

Residue changes between HsMIF and TsMIF in the active-site region have had the effect of shortening the pocket slightly and making it more hydrophobic. Specifically, changing $\mathrm{Tyr}^{99}$ in HsMIF to valine in TsMIF allows His ${ }^{97}$ (Asn in HsMIF) to flip back towards the central channel of the trimer. This allows $\mathrm{Met}^{62}$ to move into the active-site pocket. The modelled position of the hydroxy group of hydroxyphenylpyruvate, which is hydrogenbonded to $\mathrm{Asn}^{97}$ in HsMIF [35], is now very close to the sulphur atom of $\mathrm{Met}^{62}$. In addition, the side chain of $\mathrm{Leu}^{101}$ (methionine in HsMIF) is also sterically crowding the phenol moiety. Further, the change in orientation of $\mathrm{His}^{97}$ removes a polar group from the vicinity of the phenylhydroxy group, thus creating a more hydrophobic environment. These structural differences can explain the low activity of TsMIF towards $p$-hydroxyphenylpyruvate compared with phenylpyruvate (Table 3 ). Note that the important difference at position 99 (tyrosine in HsMIF as against valine in TsMIF) also occurs in TtMIF and the Brugia MIFs (Figure 1), whereas the critical $\mathrm{Asn}^{97}$ is retained in TtMIF, but is a glutamate residue in the Brugia MIFs. The altered disposition of $\mathrm{His}^{49}$ in TsMIF compared with $\mathrm{Asn}^{49}$ in HsMIF means that the putative active-site pocket of TsMIF extends right through to the central channel (Figures 4 and 5).

The large difference in tautomerase activity seen between Ldopachrome and L-dopachrome methyl ester (Table 3) can be inferred from the comparison with the phenylpyruvate structures [23]. Assuming that the carboxy-group moiety lies in approximately the same place, there is a close interaction between the 

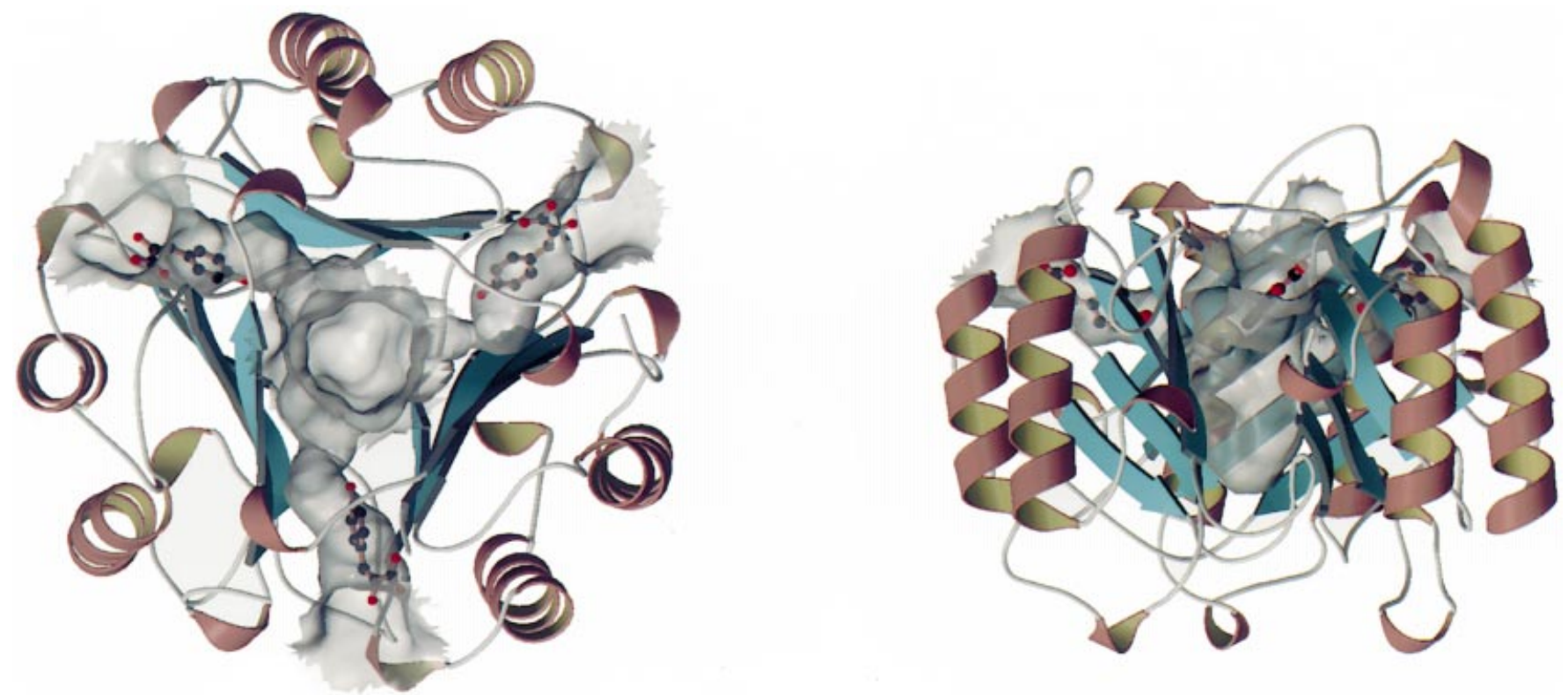

Figure 4 Top (left) and side (right) views of the channels in TsMIF superimposed on the secondary structure

p-Hydroxyphenylpyruvate from 1CA7.pdb is overlaid in the active site. The Figure was created with GRASP [48] and BOBSCRIPT [47].
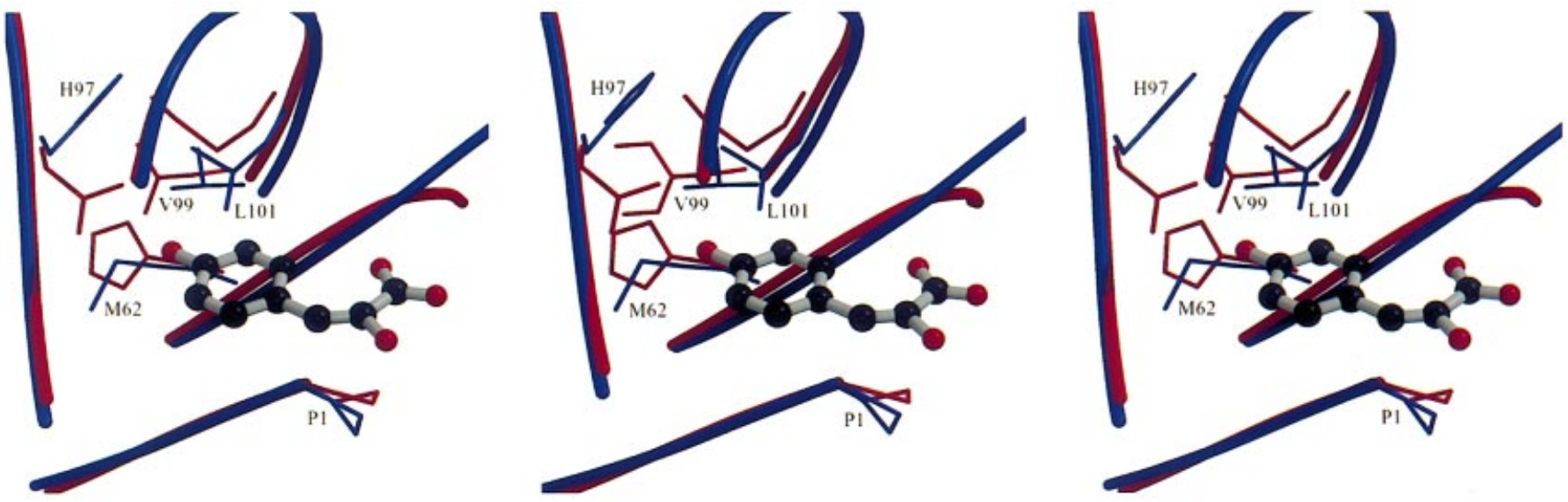

Figure 5 Superimposition of TsMIF and 1CA7.pdb active sites showing the main differences between TsMIF and HsMIF

TsMIF residues and main chain are shown in blue and those most different from those of HsMIF are labelled. The Figure was created using BOBSCRIPT [47].

carboxy hydroxy group and the side chain of $\mathrm{Ile}^{64}$. Methylating the hydroxy group would create a hydrophobic/hydrophobic contact and would also have the effect of pushing the carboxy group a little closer to Pro $^{1}$, thus increasing the probability of reaction.

\section{Cellular effects}

\section{Cell migration}

In order to discern whether TsMIF served only tautomerization functions or could also affect human immune cells as does mammalian MIF, the ability of TsMIF to alter the migration of freshly isolated normal human peripheral-blood mononuclear cells was tested using polycarbonate filter chambers. When TsMIF or HsMIF was added to the top chamber (with the monocytes), inhibition of migration was clearly seen over the full range of concentrations tested $(5 \mathrm{ng} / \mathrm{ml}$ down to $5 \mathrm{pg} / \mathrm{ml})$ with no obvious dose response (Figure 6). Similar potent effects were seen in this type of rapid assay, which is run over $3 \mathrm{~h}$ in serumfree media, when murine MIF and B. malayi MIF-1 were tested, and which implicated the tautomerase activity in the mode of inhibition of cell migration [25]. Most other studies using assays of migration which operate over $16-24 \mathrm{~h}$ in serum- or serum albumin-containing media have noted high activity only at higher concentrations (20-200 ng/ml), which are more easily interpretable in relation to levels of MIF in plasma $(1-50 \mathrm{ng} / \mathrm{ml}$; D. J. Meyer, unpublished work).

When MIF $(5 \mathrm{ng} / \mathrm{ml})$ was added to the lower chamber, monocyte migration was increased by $69 \%(P<0.0005)$ with TsMIF and by $42 \%(P<0.025)$ with rHsMIF, thus dem- 


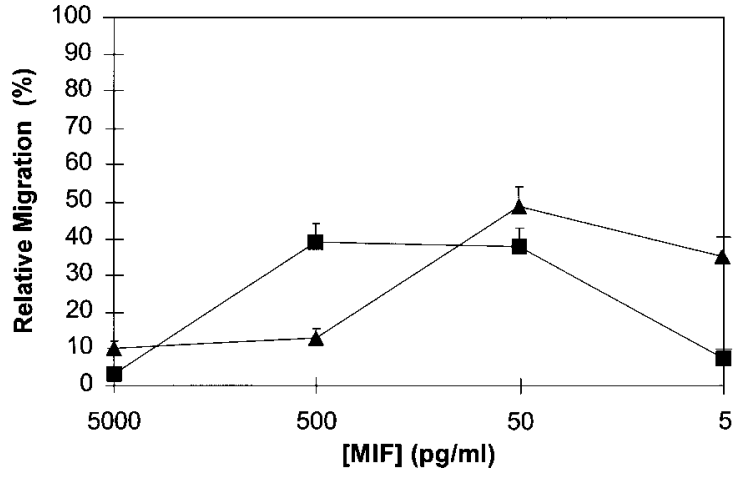

Figure 6 Migration inhibition of human monocytes

Migration of human monocytes through $5 \mu \mathrm{m}$ pores in a polycarbonate filter was determined in serum-free medium over $3 \mathrm{~h}$ as described in the text. Monocytes and MIF solution or control solution lacking MIF were added to the upper chamber. HsMIF ( $\mathbf{\square})$ and TsMIF ( significantly inhibited migration at all concentrations tested; $P$ values ranged from $10^{-4}$ to $10^{-8}$.

onstrating significant chemotactic activity as seen in a comparable assay with murine MIF or B. malayi MIF-1 [25].

\section{T-lymphocyte activation}

A number of T-cell-dependent immune parameters are depressed during trichinosis, and MIF, secreted by T-lymphocytes, has been shown to be essential for T-cell-receptor-stimulated proliferation [10]. Therefore, to test whether TsMIF might act as an immunosubversive factor, that is, an antagonist of mammalian MIF, it was incubated with murine splenocytes or with $\mathrm{CD}^{+}{ }_{-}$ positive $\mathrm{T}$ cells purified therefrom, stimulated with anti-CD3 monoclonal antibody, and subsequent proliferation measured. TsMIF in the range $5-500 \mathrm{ng} / \mathrm{ml}$, added at the same time as the activation step, had no significant effect on T-cell proliferation, nor were the levels of IL-2, IL- 4 or IFN- $\gamma$ in the cell supernatants significantly altered.

\section{TsMIF secretion}

To estimate the amounts of TsMIF which might be secreted from larvae into the host, TsMIF larvae isolated from muscle tissue were incubated in tissue culture, either with or without activation by bile. TsMIF was assayed after concentration of the spent medium and compared with the total protein secreted. TsMIF was detected at $18 \mathrm{ng} / \mathrm{mg}$ of secreted protein in the medium in the absence of bile-salt activation, and at $55 \mathrm{ng} / \mathrm{mg}$ secreted protein after bile-salt treatment. The latter value was approx. $5 \%$ of the content of TsMIF isolated from the soluble fraction of whole larvae (1160 $\mathrm{ng} / \mathrm{mg}$ of protein).

\section{DISCUSSION}

The cDNA sequences of TsMIF and TtMIF (Figure 1) are not particularly closely related according to percentage identity, but clearly share certain highly conserved residues as well as residues (discussed below) which differentiate them from mammalian MIFs, including $\mathrm{Ala}^{56}$, $\mathrm{Phe}^{59}$ (both usually cysteine), $\mathrm{Asn}^{42}, \mathrm{His}^{97}$ and $\mathrm{Va}^{99}$. Recently a phosphorylation of $\mathrm{Ser}^{89}$ of HsMIF was observed [49], and this is another residue which is different (proline) in the nematode MIFs.

rTsMIF was not distinguishable by HPLC, SDS/PAGE or specific activity towards L-dopachrome methyl ester from the native enzyme isolated from $T$. spiralis larvae, and the mass spectrum of rTsMIF gave the predicted value for an unmodified protein. Therefore it should be suitable for the analysis of structure and function of TsMIF.

Generally, evidence was obtained which showed that TsMIF has properties similar to those of human MIF. Thus TsMIF showed closely similar structure in solution and in the crystal to that of mammalian MIFs, and demonstrated a comparable tautomerase activity towards phenylpyruvate. Both TsMIF and HsMIF showed extremely potent inhibition of monocyte migration and chemotactic activity in serum-free medium, similar to that seen previously with B. malayi MIF-1 [25]. TsMIF also showed minor effects similar to those of HsMIF on bacterialendotoxin-stimulated production of nitric oxide (as nitrite) by cultured macrophages (R. Kumari and D. J. Meyer, unpublished work). The absence of effects of TsMIF upon anti-CD3stimulated $\mathrm{T}$-cell mitogenesis indicated that it is not a subversive antagonist of host MIF action, although it remains to be seen whether it has immunoglobulin-glycosylation-inhibition factor activity [49] or natural killer-cell antagonism activity [8], which might be advantageous to the parasite. Furthermore, the discovery of a partial sequence of TtMIF (a pseudogene) adjacent to a sequence homologous to the Jab1 domain of human AMSH possibly implicates TtMIF, at least in signal-transduction pathways related to cell growth, as seen for mammalian MIF [16]. With or without activation by bile (which is necessary for the acquisition of infectivity), the levels of TsMIF detected in spent medium of cultured larvae are too low compared with the intracellular level to indicate that TsMIF is primarily a secretory product under these conditions. However, the secreted amount, compared with total secreted protein, is proportionately much higher with $T$. spiralis larvae (18-55 $\mathrm{ng} / \mathrm{mg}$ of protein) than is MIF in normal human plasma (0.04-0.4 ng/mg of protein (D. J. Meyer, unpublished work) and might therefore be sufficient to affect monocyte migration locally in infected tissue.

Notable differences between TsMIF and mammalian MIFs were seen only in structural and enzymic studies. In the crystal structure, the obstruction in TsMIF of the continuous central channel of mammalian MIFs is due to hydrogen bonding between $\mathrm{Asn}^{42}$ (valine in mammalian MIFs) and the conserved Gln ${ }^{45}$. This may also occur in TtMIF and the Brugia MIFs, which also have $\mathrm{Asn}^{42}$. The relatively low tautomerase activity of TsMIF towards $p$-hydroxyphenylpyruvate appears to be due mainly to an altered disposition of residues 97 (histidine) and 62 (methionine), which are related to the change of $\operatorname{Tyr}^{99}$ to valine (Figure 5). $\mathrm{Val}^{99}$ also occurs in TtMIF and the Brugia MIFs. Hence, although residue 97 is unique to TsMIF, the extension of the active-site pocket into the central channel (Figure 4) might also occur in these MIFs. The close conservation around the active site Pro $^{1}$ and Lys ${ }^{62}$ compared with the distal regions of the pocket suggest that there are different endogenous substrates for the tautomerase activity of TsMIF and mammalian MIFs. The unidentified electron density at the active site of crystalline TsMIF might have been acquired during crystallization; however, the partial occupation of subunits observed would suggest that the ligand was bound during growth in E. coli, and any fully liganded trimers failed to bind the phenyl-agarose matrix and hence were not purified. The co-induction of tryptophan indole lyase/ $\beta$-conjugate lyase also suggests that a pathway of tryptophan metabolism or GSH conjugation was affected by the presence of TsMIF, an observation also consistent with the presence of an endogenous ligand. Further differences between TsMIF and HsMIF include the former's lower sensitivity to inhibition of tautomerase activity by haematin [34], and its relatively high activity towards L-dopachrome methyl ester (Table 
3), not seen in TtMIF. The reasons for these differences are not yet apparent. Perhaps most significant are the lack of cysteine residues. Cysteine residues at positions 56 and 59 in mammalian MIFs can participate in thiol $\leftrightarrow$ disulphide exchange with hydroxyethyl disulphide or insulin [50], and $\mathrm{Cys}^{59}$ has also been implicated in cytokine activity and the interaction with Jab1 [16]. Cysteine residues, particularly $\mathrm{Cys}^{59}$, of mammalian MIFs are important also in the acquisition of the immunoinhibitory properties of glycosylation inhibition factor (inhibition of maturation of immunoglobulins) via mixed-disulphide formation or alkylation and a natural $\mathrm{Cys}^{59}$ cysteinylated form corresponds to natural bioactive immunoglobulin glycosylation inhibition factor [49].

Taken together, the results indicate that TsMIF is partially orthologous to mammalian MIF, and it might prove useful in determining the mechanisms of action of human MIF, e.g. resolving the importance of cysteine-thiol-disulphide reactions and of the tautomerase activity. Further study will be required to determine whether TsMIF and TtMIF function in the hostparasite relationship, and whether they are potential therapeutic targets or even immunomodulatory therapeutics.

We are grateful to Quentin Bickle and Marco Albonico for collection of T. trichiura adults for TtMIF isolation; to Don Bundy and assistants for help in providing $T$. trichiura for RNA isolation, to Rachel Lawrence for the cytokine assay materials, and to Katherine Bodman-Smith and Sylvia Bino for help with monocyte and macrophage preparation. The project was supported by the Wellcome Trust (P049059) and the Biotechnology and Biological Sciences Research Council Bloomsbury Centre for Structural Biology.

\section{REFERENCES}

1 Behnke, J. M., Barnard, C. J. and Wakelin, D. (1992) Understanding chronic nematode infections: evolutionary considerations, current hypotheses and the way forward. Int. J. Parasitol. 22, 861-907

2 Maizels, R. M., Bundy, D. A. P., Selkirk, M. E., Smith, D. F. and Anderson, R. M. (1993) Immunological modulation and evasion by helminth parasites in human populations. Nature (London) 365, 797-805

3 Barriga, 0. 0. (1978) Depression of cell-mediated immunity following inoculation of Trichinella spiralis extract in the mouse. Immunology 34, 167-173

4 Gerenčer, M., Marinculić, A., Rapić, D., Franković, M. and Valpotić, I. (1992) Immunosuppression of in vivo and in vitro lymphocyte responses in swine induced by Trichinella spiralis or excretory-secretory antigens of the parasite. Vet. Parasitol. 44, 263-273

5 Pennock, J. L., Behnke, J. M., Bickle, Q. D., Devaney, E., Grencis, R. K., Isaac, R. E., Joshua, G. W. P., Selkirk, M. E., Zhang, Y. and Meyer, D. J. (1998) Rapid purification and characterization of L-dopachrome methyl ester tautomerase (macrophagemigration-inhibitory factor) from Trichinella spiralis, Trichuris muris and Brugia pahangi. Biochem. J. 335, 495-498

6 Calandra, T., Bernhagen, J., Metz, C. N., Spiegel, L. A., Bacher, M., Donelly, T., Cerami, A. and Bucala, R. (1995) MIF as a glucocorticoid-induced modulator of cytokine production. Nature (London) 377, 68-71

7 Tomura, T., Watarai, H., Honma, N., Sato, M., Iwamatsu, A., Kato, Y., Kuroki, R., Nakano, T., Mikayama, T. and Ishizaka, K. (1999) Immunosuppressive activities of recombinant glycosylation-inhibiting factor mutants. J. Immunol. 162, 195-202

8 Apte, R. S., Sinha, D., Mayhew, E., Wistow, G. J. and Niederkorn, J. Y. (1998) Role of macrophage migration inhibitory factor in inhibiting NK cell activity and preserving immune privilege. J. Immunol. 160, 5693-5696

9 Hudson, J. D., Shoaibi, M. A., Maestro, R., Carnero, A., Hannon, G. J. and Beach, D. H. (1999) A proinflammatory cytokine inhibits p53 tumour suppressor activity. J. Exp. Med. 190, 1375-1382

10 Bacher, M., Metz, C. N., Calandra, T., Mayer, K., Chesney, J., Lohoff, M., Gemsa, D., Donelly, T. and Bucala, R. (1996) An essential regulatory role for macrophage migration inhibitory factor in T-cell activation. Proc. Natl. Acad. Sci. U.S.A. 93, 7849-7854

11 Waeber, G., Calandra, T., Roduit, R., Haefliger, J.-A., Bonny, C., Thompson, N., Thorens, B., Temler, E., Meinhardt, A., Bacher, M., Metz, C. N., Nicod, P. and Bucala, R. (1997) Insulin secretion is regulated by the glucose-dependent production of islet $\beta$ cell macrophage migration inhibitory factor. Proc. Natl. Acad. Sci. U.S.A. 94, 4782-4787
12 Chesney, J., Metz, C., Bacher, M., Peng, T., Meinhardt, A. and Bucala, R. (1999) An essential role for macrophage migration inhibitory factor (MIF) in angiogenesis and the growth of a murine lymphoma. Mol. Med. 5, 181-191

13 Mitchell, R. A., Metz, C. N., Peng, T. and Bucala, R. (1999) Sustained mitogenactivated protein kinase (MAPK) and cytoplasmic phospholipase $A_{2}$ activation by macrophage migration inhibitory factor. J. Biol. Chem. 274, 18100-18106

14 Bozza, M., Satoskar, A. R., Lin, G., Lu, B., Humbles, A. A., Gerard, C. and David, J. R. (1999) Targeted disruption of migration inhibitory factor gene reveals its critical role in sepsis. J. Exp. Med. 189, 341-346

15 Cunha, F. Q., Weiser, Y. W., David, J. R., Moss, D. W, Moncada, S. and Liew, F. Y. (1993) Recombinant migration inhibitory factor induces nitric oxide synthase in murine macrophages. J. Immunol. 150, 1908-1912

16 Kleeman, R., Hausser, A., Geiger, G., Mishcke, R., Burger-Kentischer, A., Flieger, 0. Johannes, F.-J., Roger, T., Calandra, T., Kapurniotu, A. et al. (2000) Intracellular action of the cytokine MIF to modulate AP-1 activity and the cell cycle through Jab1. Nature (London) 408, 211-216

17 Esumi, N., Budarf, M., Ciccarelli, L., Sellinger, B., Kozak, C. A. and Wistow, G (1998) Conserved gene structure and genomic linkage for D-dopachrome tautomerase (DDT) and MIF. Mammal. Genome 9, 753-757

18 Coggan, M., Whitbread, L., Whittington, A. and Board, P. (1998) Structure and organization of the human theta-class glutathione S-transferase and D-dopachrome tautomerase complex. Biochem. J. 334, 617-623

19 Sugimoto, H., Taniguchi, M., Nakagawa, A., Tanaka, I., Suzuki, M. and Nishihara, J. (1999) Crystal structure of human D-dopachrome tautomerase, a homologue of macrophage migration inhibitory factor, at $1.54 \AA$ resolution. Biochemistry $\mathbf{3 8}$ 3268-3279

20 Sun, H-W., Bernhagen, J., Bucala, R. and Lolis, E. (1996) Crystal structure at 2.6-A resolution of human macrophage migration inhibitory factor. Proc. Natl. Acad. Sci. U.S.A. 93, 5191-5196

21 Kato, Y., Muto, T., Tomura, T., Watarai, H., Mikayama, T., Ishizaka, K. and Kuroki, R. (1996) The crystal structure of human glycosylation-inhibiting factor is a trimeric barrel with three 6-stranded $\beta$-sheets. Proc. Natl. Acad. Sci. U.S.A. 93, 3007-3010

22 Bendrat, K., Al-Abed, Y., Callaway, D. J. E., Peng, T., Calandra, T., Metz, C. N. and Bucala, R. (1997) Biochemical and mutational investigations of the enzymatic activity of macrophage migration inhibitory factor. Biochemistry 36, 15356-15362

23 Lubetsky, J. B., Swope, M., Dealwis, C., Blake, P. and Lolis, E. (1999) Pro-1 of macrophage migration inhibitory factor functions as a catalytic base in the phenylpyruvate tautomerase activity. Biochemistry 38, 7346-7354

24 Johnson, W. H., Czerwinski, R. M., Stamps, S. L. and Whitman, C. P. (1999) A kinetic and stereochemical investigation of lysine-32 in the phenylpyruvate tautomerase activity catalysed by macrophage migration inhibitory factor. Biochemistry 38, 16024-16033

25 Pastrana, D. V., Raghavan, N., Fitzgerald, P., Eisinger, S. W., Metz, C., Bucala, R., Schleimer, R. P., Bickel, C. and Scott, A. L. (1998) Filarial nematode parasites secrete a homologue of the human cytokine macrophage migration inhibitory factor. Infect. Immun. 66, 5955-5963

26 Arden, S. R., Smith, A. M., Booth, M. J., Tweedie, S., Gounaris, K. and Selkirk, M. E. (1997) Identification of serine/threonine protein kinases secreted by Trichinella spiralis infective larvae. Mol. Biochem. Parasitol. 90, 111-119

27 Totty, N. F., Waterfield, M. D. and Hsuan, J. J. (1992) Accelerated high-sensitivity microsequencing of proteins and peptides using a miniature reaction cartridge. Protein Sci. 1, 1215-1224

28 Su, X. Z., Prestwood, A. K. and McGraw, R. A. (1991) Cloning and expression of complementary DNA encoding an antigen of Trichinella spiralis. Mol. Biochem. Parasitol. 45, 331-336

29 Habeeb, A. F. S. A. (1972) Reaction of protein sulphydryl groups with Ellman's reagent. Methods Enzymol. 25, 457-469

30 Ashton, D. S., Beddell, R. C., Green, B. N. and Oliver, R. W. A. (1994) Rapid validation of molecular structures of biological samples by electrospray-mass spectrometry. FEBS Lett. 342, 1-6

31 Wallace, B. A. and Teeters, C. L. (1987) Differential absorption flattening optical effects are significant in the circular dichroism spectra of large membrane fragments. Biochemistry 26, 65-70

32 Hennessey, Jr J. P. and Johnson, Jr W. C. (1982) Experimental errors and their effect on analyzing circular dichroism spectra of proteins. Anal. Biochem. 125, 177-188

33 Brahms, S. and Brahms, J. (1980) Determination of protein secondary structure in solution by vacuum ultraviolet circular dichroism. J. Mol. Biol. 138, 149-178

34 Pennock, J. L., Wipasa, J., Gordge, M. P. and Meyer, D. J. (1998) Interaction of macrophage-migration-inhibitory factor with haematin. Biochem. J. 331, 905-908

35 Taylor, A. B., Johnson, Jr W. H., Czerwinski, R. M., Li, H.-S., Hackert, M. L. and Whitman, C. P. (1999) Crystal structure of macrophage migration inhibitory factor complexed with $(E)$-2-fluoro-p-hydroxycinnamic acid at $1.8 \AA$ resolution: implications for enzymatic catalysis and inhibition. Biochemistry 38, 7444-7452

36 Jancarik, K. and Kim, S.-H. (1991) Sparse matrix sampling: a screening method for crystallisation of proteins (1991). J. Appl. Crystallogr. 24, 409-411 
37 Matthews, B. W. (1969) Solvent content of protein crystals. J. Mol. Biol. 33 491-497

38 Collaborative Computational Project Number 4 (1994) The CCP4 suite: programs for protein crystallography. Acta Crystallogr. D50, 760-763

39 Brünger, A. T., Adams, P. D., Clore, G. M., DeLano, W. L., Gros, P., Grosse-Kunstleve, R. W., Jiang, J.-S., Kuszewski, J., Nilges, M., Pannu, N. S. et al. (1998) Crystallography and NMR System: A new software suite for macromolecular structure determination. Acta Crystallogr. D54, 905-921

40 Jones, T. A., Zou, J. Y., Cowan, S. W. and Kjeldgaard, M. (1991) Improved methods for building protein models in electron density maps and the location of errors in these models. Acta Crystallogr. A47, 110-119

41 Mak, C. H. and Ko, R. C. (1999) Characterization of endonuclease activity from excretory/secretory products of a parasitic nematode, Trichinella spiralis. Eur. J. Biochem. 260, 477-481

42 Tanaka, N., Kaneko, K., Asao, H., Kasai, H., Endo, Y., Fujita, T., Takeshita, T. and Sugamura, K. (1999) Possible involvement of a novel STAM-associated molecule 'AMSH' in intracellular signal transduction mediated by cytokines. J. Biol. Chem. 274, 19129-19135

43 Mischke, R., Gessner, A., Kapurniotu, A., Juttner, S., Kleemann, R., Brunner, H. and Bernhagen, J. (1997) Structure activity studies of the cytokine macrophage migration inhibitory factor (MIF) reveal a critical role for its carboxy terminus. FEBS Lett. $\mathbf{4 1 4}$ 226-232
44 Yang, J. T., Wu, C. S. and Martinez, H. M. (1986) Calculation of protein conformation from circular dichroism. Methods Enzymol. 130, 208-269

45 Sun, H. W., Swope, M., Cinquina, C., Bedarkar, S., Bernhagen, J., Bucala, R. and Lolis, E. (1996) The subunit structure of human macrophage migration inhibitory factor: evidence for a trimer. Protein Eng. 9, 631-635

46 Kabsch, W. and Sander, C. (1983) Dictionary of protein secondary structure: pattern recognition of hydrogen-bonded and geometrical features. Biopolymers 12, 2577-2637

47 Esnouf, R. M. (1999) Further additions to MolScript version 1.4, including reading and contouring of electron density maps. (1999). Acta Crystallogr. D55, 938-940

48 Nicholls, A., Sharp, K. A. and Honig, B. (1991) Protein folding and association: insights from the interfacial and thermodynamic properties of hydrocarbons. Proteins 11, 281-296

49 Watarai, H., Nozawa, R., Tokunaga, A., Yuyama, N., Tomas, M., Hinohara, A., Ishizaki, K. and Ishii, Y. (2000) Posttranslational modification of the glycosylation inhibiting factor (GIF) gene product generates bioactive GIF. Proc. Natl. Acad. Sci. U.S.A. 97 13251-13256

50 Kleeman, R., Kapurniotu, A., Frank, R. W., Gessner, A., Mischke, R., Flieger, O., Juttner, S., Brunner, H. and Bernhagen, J. (1998) Disulfide analysis reveals a role for macrophage migration inhibitory factor (MIF) as thiol-protein oxidoreductase. J. Mol. Biol. 280, 85-102

Received 12 January 2001/12 March 2001; accepted 26 April 2001 